\title{
Best proximity points for Geraghty's proximal contraction mappings
}

\author{
Chirasak Mongkolkeha ${ }^{1,3}$, Yeol Je Cho ${ }^{2^{*}}$ and Poom Kumam ${ }^{\text {1* }}$
}

"Correspondence: yjcho@gnu.ac.kr; poom.kum@kmutt.ac.th

${ }^{1}$ Department of Mathematics, Faculty of Science, King Mongkut's University of Technology Thonburi (KMUTT), Bang Mod, Bangkok, 10140, Thailand

${ }^{2}$ Department of Mathematics Education and the RINS, Gyeongsang National University, Chinju, 660-701, Korea Full list of author information is available at the end of the article

\begin{abstract}
In this paper, we generalized the notion of proximal contractions of the first and second kinds by using Geraghty's theorem and establish best proximity point theorems for proximal contractions. Our results improve and extend the recent results of Sadiq Basha and some others.
\end{abstract}

MSC: $47 \mathrm{H} 09 ; 47 \mathrm{H} 10$

Keywords: fixed point; best proximity point; Geraghty's proximal contraction mapping; proximal contraction mapping

\section{Introduction}

Several problems can be modeled as equations of the form $T x=x$, where $T$ is a given self-mapping defined on a subset of a metric space, a normed linear space, a topological vector space or some suitable space. However, if $T$ is a nonself-mapping from $A$ to $B$, then the aforementioned equation does not necessarily admit a solution. In this case, it is contemplated to find an approximate solution $x$ in $A$ such that the error $d(x, T x)$ is minimum, where $d$ is the distance function. In view of the fact that $d(x, T x)$ is at least $d(A, B)$, a best proximity point theorem guarantees the global minimization of $d(x, T x)$ by the requirement that an approximate solution $x$ satisfies the condition $d(x, T x)=d(A, B)$. Such optimal approximate solutions are called best proximity points of the mapping $T$. Interestingly, best proximity theorems also serve as a natural generalization of fixed point theorems, for a best proximity point becomes a fixed point if the mapping under consideration is a self-mapping.

A classical best approximation theorem was introduced by Fan [1], that is, if $A$ is a nonempty compact convex subset of a Hausdorff locally convex topological vector space $B$ and $T: A \rightarrow B$ is a continuous mapping, then there exists an element $x \in A$ such that $d(x, T x)=d(T x, A)$. Afterward, several authors, including Prolla [2], Reich [3], Sehgal and Singh $[4,5]$, derived the extensions of Fan's theorem in many directions. Other works on the existence of a best proximity point for contractions can be seen in [6-14].

In 1922, Banach proved that every contractive mapping in a complete metric spaces has a unique fixed point, which is called Banach's fixed point theorem or Banach's contraction principle. Since Banach's fixed point theorem, many authors have extended, improved and generalized this theorem in several ways. Some applications of Banach's fixed point theorem can be found in [15-18]. One of such generalizations is due to Geraghty [19] as follows. 
Theorem 1.1 [19] Let $(X, d)$ be a complete metric space and let $f$ be a self-mapping on $X$ such that for each $x, y \in X$ satisfying

$$
d(f x, f y) \leq \alpha(d(x, y)) d(x, y)
$$

where $\alpha \in \mathcal{S}, \mathcal{S}$ is the family of functions from $[0, \infty)$ into $[0,1)$ which satisfies the condition

$$
\alpha\left(t_{n}\right) \rightarrow 1 \quad \Rightarrow \quad t_{n} \rightarrow 0
$$

Then the sequence $\left\{f_{n}\right\}$ converges to the unique fixed point off in $X$.

In 2005, Eldred et al. [20] obtained best proximity point theorems for relatively nonexpansive mappings. Best proximity point theorems for several types of contractions were established in [21-25].

Recently, Sadiq Basha in [26] gave necessary and sufficient conditions to claim the existence of a best proximity point for proximal contractions of the first kind and the second kind, which are non-self mapping analogues of contraction self-mappings, and also established some best proximity and convergence theorems.

The aim of this paper is to introduce the new classes of proximal contractions, which are more general than a class of proximal contractions of the first and second kinds, by giving the necessary condition to have best proximity points, and we also give some illustrative example of our main results. The results of this paper are extension and generalizations of the main result of Sadiq Basha in [26] and some results in the literature.

\section{Preliminaries}

Given nonempty subsets $A$ and $B$ of a metric space $(X, d)$, we recall the following notations and notions that will be used in what follows.

$$
\begin{aligned}
& d(A, B):=\inf \{d(x, y): x \in A \text { and } y \in B\}, \\
& A_{0}:=\{x \in A: d(x, y)=d(A, B) \text { for some } y \in B\}, \\
& B_{0}:=\{y \in B: d(x, y)=d(A, B) \text { for some } x \in A\} .
\end{aligned}
$$

If $A \cap B \neq \emptyset$, then $A_{0}$ and $B_{0}$ are nonempty. Further, it is interesting to notice that $A_{0}$ and $B_{0}$ are contained in the boundaries of $A$ and $B$, respectively, provided $A$ and $B$ are closed subsets of a normed linear space such that $d(A, B)>0$ (see [27]).

Definition 2.1 [26] A mapping $T: A \rightarrow B$ is called a proximal contraction of the first kind if there exists $k \in[0,1)$ such that

$$
\left.\begin{array}{l}
d(u, T x)=d(A, B) \\
d(v, T y)=d(A, B)
\end{array}\right\} \quad \Longrightarrow \quad d(u, v) \leq k d(x, y)
$$

for all $u, v, x, y \in A$.

It is easy to see that a self-mapping that is a proximal contraction of the first kind is precisely a contraction. However, a nonself-proximal contraction is not necessarily a contraction. 
Definition 2.2 [26] A mapping $T: A \rightarrow B$ is called a proximal contraction of the second kind if there exists $k \in[0,1)$ such that

$$
\left.\begin{array}{l}
d(u, T x)=d(A, B) \\
d(v, T y)=d(A, B)
\end{array}\right\} \quad \Rightarrow \quad d(T u, T v) \leq k d(T x, T y)
$$

for all $a, b, x, y \in A$.

Definition 2.3 Let $S: A \rightarrow B$ and $T: B \rightarrow A$ be mappings. The pair $(S, T)$ is called a proximal cyclic contraction pair if there exists $k \in[0,1)$ such that

$$
\left.\begin{array}{l}
d(a, S x)=d(A, B) \\
d(b, T y)=d(A, B)
\end{array}\right\} \quad \Rightarrow \quad d(a, b) \leq k d(x, y)+(1-k) d(A, B)
$$

for all $a, x \in A$ and $b, y \in B$.

Definition 2.4 Let $S: A \rightarrow B$ and $g: A \rightarrow A$ be an isometry. The mapping $S$ is said to preserve the isometric distance with respect to $g$ if

$$
d(\operatorname{Sgx}, \operatorname{Sgy})=d(S x, S y)
$$

for all $x, y \in A$.

Definition 2.5 A point $x \in A$ is called a best proximity point of the mapping $S: A \rightarrow B$ if it satisfies the condition that

$$
d(x, S x)=d(A, B)
$$

It can be observed that a best proximity reduces to a fixed point if the underlying mapping is a self-mapping.

\section{Main results}

In this section, we introduce a new class of proximal contractions, the so-called Geraghty's proximal contraction mappings, and prove best proximity theorems for this class.

Definition 3.1 A mapping $T: A \rightarrow B$ is called Geraghty's proximal contraction of the first kind if, there exists $\beta \in \mathcal{S}$ such that

$$
\left.\begin{array}{l}
d(u, T x)=d(A, B) \\
d(v, T y)=d(A, B)
\end{array}\right\} \quad \Rightarrow \quad d(u, v) \leq \beta(d(x, y)) d(x, y)
$$

for all $u, v, x, y \in A$.

Definition 3.2 A mapping $T: A \rightarrow B$ is called Geraghty's proximal contraction of the second kind if, there exists $\beta \in \mathcal{S}$ such that

$$
\left.\begin{array}{l}
d(u, T x)=d(A, B) \\
d(v, T y)=d(A, B)
\end{array}\right\} \quad \Rightarrow \quad d(T u, T v) \leq \beta(d(T x, T y)) d(T x, T y)
$$

for all $u, v, x, y \in A$. 
It is easy to see that if we take $\beta(t)=k$, where $k \in[0,1)$, then Geraghty's proximal contraction of the first kind and Geraghty's proximal contraction of the second kind reduce to a proximal contraction of the first kind (Definition 2.1) and a proximal contraction of the second kind (Definition 2.2), respectively.

Next, we extend the result of Sadiq Basha [26] and Banach's fixed point theorem to the case of nonself-mappings satisfying Geraghty's proximal contraction condition.

Theorem 3.3 Let $(X, d)$ be a complete metric space and let $A, B$ be nonempty closed subsets of $X$ such that $A_{0}$ and $B_{0}$ are nonempty. Let $S: A \rightarrow B, T: B \rightarrow A$ and $g: A \cup B \rightarrow A \cup B$ satisfy the following conditions:

(a) S and T are Geraghty's proximal contractions of the first kind;

(b) $g$ is an isometry;

(c) the pair $(S, T)$ is a proximal cyclic contraction;

(d) $S\left(A_{0}\right) \subseteq B_{0}, T\left(B_{0}\right) \subseteq A_{0}$;

(e) $A_{0} \subseteq g\left(A_{0}\right)$ and $B_{0} \subseteq g\left(B_{0}\right)$.

Then there exists a unique point $x \in A$ and there exists a unique point $y \in B$ such that

$$
d(g x, S x)=d(g y, T y)=d(x, y)=d(A, B) .
$$

Moreover, for any fixed $x_{0} \in A_{0}$, the sequence $\left\{x_{n}\right\}$ defined by

$$
d\left(g x_{n+1}, S x_{n}\right)=d(A, B)
$$

converges to the element $x$. For any fixed $y_{0} \in B_{0}$, the sequence $\left\{y_{n}\right\}$ defined by

$$
d\left(g y_{n+1}, T y_{n}\right)=d(A, B)
$$

converges to the element $y$.

On the other hand, a sequence $\left\{u_{n}\right\}$ in A converges to $x$ if there exists a sequence of positive numbers $\left\{\epsilon_{n}\right\}$ such that

$$
\lim _{n \rightarrow \infty} \epsilon_{n}=0, \quad d\left(u_{n+1}, z_{n+1}\right) \leq \epsilon_{n}
$$

where $z_{n+1} \in A$ satisfies the condition that $d\left(g z_{n+1}, S u_{n}\right)=d(A, B)$.

Proof Let $x_{0}$ be a fixed element in $A_{0}$. In view of the fact that $S\left(A_{0}\right) \subseteq B_{0}$ and $A_{0} \subseteq g\left(A_{0}\right)$, it follows that there exists an element $x_{1} \in A_{0}$ such that

$$
d\left(g x_{1}, S x_{0}\right)=d(A, B) .
$$

Again, since $S\left(A_{0}\right) \subseteq B_{0}$ and $A_{0} \subseteq g\left(A_{0}\right)$, there exists an element $x_{2} \in A_{0}$ such that

$$
d\left(g x_{2}, S x_{1}\right)=d(A, B) .
$$

By the same method, we can find $x_{n}$ in $A_{0}$ such that

$$
d\left(g x_{n}, S x_{n-1}\right)=d(A, B) .
$$


So, inductively, one can determine an element $x_{n+1} \in A_{0}$ such that

$$
d\left(g x_{n+1}, S x_{n}\right)=d(A, B) .
$$

Since $S\left(A_{0}\right) \subseteq B_{0}$ and $A_{0} \subseteq g\left(A_{0}\right), S$ is Geraghty's proximal contraction of the first kind, $g$ is an isometry and the property of $\beta$, it follows that for each $n \geq 1$

$$
\begin{aligned}
d\left(x_{n+1}, x_{n}\right) & =d\left(g x_{n+1}, g x_{n}\right) \\
& \leq \beta\left(d\left(x_{n}, x_{n-1}\right)\right) d\left(x_{n}, x_{n-1}\right) \\
& \leq d\left(x_{n}, x_{n-1}\right),
\end{aligned}
$$

which implies that the sequence $\left\{d\left(x_{n+1}, x_{n}\right)\right\}$ is non-increasing and bounded below. Hence there exists $r \geq 0$ such that $\lim _{n \rightarrow \infty} d\left(x_{n+1}, x_{n}\right)=r$. Suppose that $r>0$. Observe that

$$
\frac{d\left(x_{n+1}, x_{n}\right)}{d\left(x_{n}, x_{n-1}\right)} \leq \beta\left(d\left(x_{n}, x_{n-1}\right)\right)
$$

which implies that $\lim _{n \rightarrow \infty} \beta\left(d\left(x_{n}, x_{n-1}\right)\right)=1$. Since $\beta \in \mathcal{S}$, we have $r=0$ which is a contradiction and hence

$$
\lim _{n \rightarrow \infty} d\left(x_{n-1}, x_{n}\right)=0
$$

Now, we claim that $\left\{x_{n}\right\}$ is a Cauchy sequence. Suppose that $\left\{x_{n}\right\}$ is not a Cauchy sequence. Then there exists $\varepsilon>0$ and subsequences $\left\{x_{m_{k}}\right\},\left\{x_{n_{k}}\right\}$ of $\left\{x_{n}\right\}$ such that for any $n_{k}>m_{k} \geq k$

$$
r_{k}:=d\left(x_{m_{k}}, x_{n_{k}}\right) \geq \varepsilon, \quad d\left(x_{m_{k}}, x_{n_{k}-1}\right)<\varepsilon
$$

for any $k \in\{1,2,3, \ldots\}$. For each $n \geq 1$, let $\alpha_{n}:=d\left(x_{n+1}, x_{n}\right)$. Then we have

$$
\begin{aligned}
\varepsilon & \leq r_{k} \leq d\left(x_{m_{k}}, x_{n_{k}-1}\right)+d\left(x_{n_{k}-1}, x_{n_{k}}\right) \\
& <\varepsilon+\alpha_{n_{k}-1}
\end{aligned}
$$

and so it follows from (3.2) and (3.3) that

$$
\lim _{k \rightarrow \infty} r_{k}=\varepsilon
$$

Notice also that

$$
\begin{aligned}
\varepsilon & \leq r_{k} \\
& \leq d\left(x_{m_{k}}, x_{m_{k}+1}\right)+d\left(x_{n_{k}+1}, x_{n_{k}}\right)+d\left(x_{m_{k}+1}, x_{n_{k}+1}\right) \\
& =\alpha_{m_{k}}+\alpha_{n_{k}}+d\left(x_{m_{k}+1}, x_{n_{k}+1}\right) \\
& \leq \alpha_{m_{k}}+\alpha_{n_{k}}+\beta\left(d\left(x_{m_{k}}, x_{n_{k}}\right)\right) d\left(x_{m_{k}}, x_{n_{k}}\right)
\end{aligned}
$$


and so

$$
\frac{r_{k}-\alpha_{m_{k}}-\alpha_{n_{k}}}{d\left(x_{m_{k}}, x_{n_{k}}\right)} \leq \beta\left(d\left(x_{m_{k}}, x_{n_{k}}\right)\right) .
$$

Taking $k \rightarrow \infty$ in the above inequality, by (3.2), (3.4) and $\beta \in \mathcal{S}$, we get $\varepsilon=0$, which is a contradiction. So we know that the sequence $\left\{x_{n}\right\}$ is a Cauchy sequence. Hence $\left\{x_{n}\right\}$ converges to some element $x \in A$.

Similarly, in view of the fact that $T\left(B_{0}\right) \subseteq A_{0}$ and $A_{0} \subseteq g\left(A_{0}\right)$, we can conclude that there exists a sequence $\left\{y_{n}\right\}$ such that it converges to some element $y \in B$. Since the pair $(S, T)$ is a proximal cyclic contraction and $g$ is an isometry, we have

$$
d\left(x_{n+1}, y_{n+1}\right)=d\left(g x_{n+1}, g y_{n+1}\right) \leq k d\left(x_{n}, y_{n}\right)+(1-k) d(A, B) .
$$

Taking $n \rightarrow \infty$ in (3.5), it follows that

$$
d(x, y)=d(A, B)
$$

and so $x \in A_{0}$ and $y \in B_{0}$. Since $S\left(A_{0}\right) \subseteq B_{0}$ and $T\left(B_{0}\right) \subseteq A_{0}$, there exist $u \in A$ and $v \in B$ such that

$$
d(u, S x)=d(A, B), \quad d(v, T y)=d(A, B) .
$$

From (3.1) and (3.7), since $S$ is Geraghty's proximal contraction of the first kind of $S$, we get

$$
d\left(u, g x_{n+1}\right) \leq \beta\left(d\left(x, x_{n}\right)\right) d\left(x, x_{n}\right) .
$$

Letting $n \rightarrow \infty$ in the above inequality, we get $d(u, g x) \leq 0$ and so $u=g x$. Therefore, we have

$$
d(g x, S x)=d(A, B) .
$$

Similarly, we can show that $v=g y$ and so

$$
d(g y, T y)=d(A, B) .
$$

From (3.6), (3.9) and (3.10), we get

$$
d(x, y)=d(g x, S x)=d(g y, T y)=d(A, B) .
$$

Next, to prove the uniqueness, suppose that there exist $x^{*} \in A$ and $y^{*} \in B$ with $x \neq x^{*}$ and $y \neq y^{*}$ such that

$$
d\left(g x^{*}, S x^{*}\right)=d(A, B), \quad d\left(g y^{*}, T y^{*}\right)=d(A, B) .
$$


Since $g$ is an isometry and $S$ is Geraghty's proximal contraction of the first kind, it follows that

$$
d\left(x, x^{*}\right)=d\left(g x, g x^{*}\right) \leq \beta\left(d\left(x, x^{*}\right)\right) d\left(x, x^{*}\right)
$$

and hence

$$
1=\frac{d\left(x, x^{*}\right)}{d\left(x, x^{*}\right)} \leq \beta\left(d\left(x, x^{*}\right)\right)<1,
$$

which is a contradiction. Thus we have $x=x^{*}$. Similarly, we can prove that $y=y^{*}$.

On the other hand, let $\left\{u_{n}\right\}$ be a sequence in $A$ and $\left\{\epsilon_{n}\right\}$ be a sequence of positive real numbers such that

$$
\lim _{n \rightarrow \infty} \epsilon_{n}=0, \quad d\left(u_{n+1}, z_{n+1}\right) \leq \epsilon_{n},
$$

where $z_{n+1} \in A$ satisfies the condition that

$$
d\left(g z_{n+1}, S u_{n}\right)=d(A, B)
$$

By (3.1) and (3.12), since $S$ is Geraghty's proximal contraction of the first kind and $g$ is an isometry, we have

$$
d\left(x_{n+1}, z_{n+1}\right)=d\left(g x_{n+1}, g z_{n+1}\right) \leq \beta\left(d\left(x_{n}, u_{n}\right)\right) d\left(x_{n}, u_{n}\right) .
$$

For any $\epsilon>0$, choose a positive integer $N$ such that $\epsilon_{n} \leq \epsilon$ for all $n \geq N$. Observe that

$$
\begin{aligned}
d\left(x_{n+1}, u_{n+1}\right) & \leq d\left(x_{n+1}, z_{n+1}\right)+d\left(z_{n+1}, u_{n+1}\right) \\
& \leq \beta\left(d\left(x_{n}, u_{n}\right)\right) d\left(x_{n}, u_{n}\right)+\epsilon_{n} \\
& \leq d\left(x_{n}, u_{n}\right)+\epsilon .
\end{aligned}
$$

Since $\epsilon>0$ is arbitrary, we can conclude that for all $n \geq N$ the sequence $\left\{d\left(x_{n}, u_{n}\right)\right\}$ is nonincreasing and bounded below and hence converges to some nonnegative real number $r^{\prime}$. Since the sequence $\left\{x_{n}\right\}$ converges to $x$, we get

$$
\lim _{n \rightarrow \infty} d\left(u_{n}, x\right)=\lim _{n \rightarrow \infty} d\left(u_{n}, x_{n}\right)=r^{\prime} .
$$

Suppose that $r^{\prime}>0$. Since

$$
\begin{aligned}
d\left(u_{n+1}, x\right) & \leq d\left(u_{n+1}, x_{n+1}\right)+d\left(x_{n+1}, x\right) \\
& \leq \beta\left(d\left(x_{n}, u_{n}\right)\right) d\left(x_{n}, u_{n}\right)+\epsilon_{n}+d\left(x_{n+1}, x\right),
\end{aligned}
$$

it follows from inequalities (3.11), (3.13) and (3.14) that

$$
\frac{d\left(u_{n+1}, x\right)-\epsilon_{n}-d\left(x_{n+1}, x\right)}{d\left(x_{n}, u_{n}\right)} \leq \beta\left(d\left(x_{n}, u_{n}\right)\right)<1,
$$


which implies that $\beta\left(d\left(x_{n}, u_{n}\right)\right) \rightarrow 1$ and so $d\left(u_{n}, x_{n}\right) \rightarrow 0$, that is,

$$
\lim _{n \rightarrow \infty} d\left(u_{n}, x\right)=\lim _{n \rightarrow \infty} d\left(u_{n}, x_{n}\right)=0,
$$

which is a contradiction. Thus $r^{\prime}=0$ and hence $\left\{u_{n}\right\}$ is convergent to the point $x$. This completes the proof.

If $g$ is the identity mapping in Theorem 3.3, then we obtain the following.

Corollary 3.4 Let $(X, d)$ be a complete metric space and let $A, B$ be nonempty closed subsets of $X$. Further, suppose that $A_{0}$ and $B_{0}$ are nonempty. Let $S: A \rightarrow B, T: B \rightarrow A$ and $g$ : $A \cup B \rightarrow A \cup B$ be the mappings satisfying the following conditions:

(a) $S$ and $T$ are Geraghty's proximal contractions of the first kind;

(b) $S\left(A_{0}\right) \subseteq B_{0}, T\left(B_{0}\right) \subseteq A_{0}$;

(c) the pair $(S, T)$ is a proximal cyclic contraction.

Then there exists a unique point $x \in A$ and there exists a unique point $y \in B$ such that

$$
d(x, S x)=d(y, T y)=d(x, y)=d(A, B) .
$$

If we take $\beta(t)=k$, where $0 \leq k<1$, we obtain the following corollary.

Corollary 3.5 [26] Let $(X, d)$ be a complete metric space and let $A, B$ be nonempty closed subsets of $X$. Further, suppose that $A_{0}$ and $B_{0}$ are nonempty. Let $S: A \rightarrow B, T: B \rightarrow A$ and $g: A \cup B \rightarrow A \cup B$ be the mappings satisfying the following conditions:

(a) $S$ and $T$ are proximal contractions of the first kind;

(b) $g$ is an isometry;

(c) the pair $(S, T)$ is a proximal cyclic contraction;

(d) $S\left(A_{0}\right) \subseteq B_{0}, T\left(B_{0}\right) \subseteq A_{0}$;

(e) $A_{0} \subseteq g\left(A_{0}\right)$ and $B_{0} \subseteq g\left(B_{0}\right)$.

Then there exists a unique point $x \in A$ and there exists a unique point $y \in B$ such that

$$
d(g x, S x)=d(g y, T y)=d(x, y)=d(A, B) .
$$

Moreover, for any fixed $x_{0} \in A_{0}$, the sequence $\left\{x_{n}\right\}$ defined by

$$
d\left(g x_{n+1}, S x_{n}\right)=d(A, B)
$$

converges to the element $x$. For any fixed $y_{0} \in B_{0}$, the sequence $\left\{y_{n}\right\}$ defined by

$$
d\left(g y_{n+1}, T y_{n}\right)=d(A, B)
$$

converges to the element $y$.

If $g$ is the identity mapping in Corollary 3.5, we obtain the following corollary.

Corollary 3.6 Let $(X, d)$ be a complete metric space and let $A, B$ be nonempty closed subsets of $X$. Further, suppose that $A_{0}$ and $B_{0}$ are nonempty. Let $S: A \rightarrow B, T: B \rightarrow A$ and $g$ : $A \cup B \rightarrow A \cup B$ be the mappings satisfying the following conditions: 
(a) $S$ and $T$ are proximal contractions of the first kind;

(b) $S\left(A_{0}\right) \subseteq B_{0}, T\left(B_{0}\right) \subseteq A_{0}$;

(c) the pair $(S, T)$ is a proximal cyclic contraction.

Then there exists a unique point $x \in A$ and there exists a unique point $y \in B$ such that

$$
d(x, S x)=d(y, T y)=d(x, y)=d(A, B) .
$$

Next, we establish a best proximity point theorem for nonself-mappings which are Geraghty's proximal contractions of the first kind and the second kind.

Theorem 3.7 Let $(X, d)$ be a complete metric space and let $A, B$ be nonempty closed subsets of $X$. Further, suppose that $A_{0}$ and $B_{0}$ are nonempty. Let $S: A \rightarrow B$ and $g: A \rightarrow A$ be the mappings satisfying the following conditions:

(a) S is Geraghty's proximal contraction of the first and second kinds;

(b) $g$ is an isometry;

(c) $S$ preserves isometric distance with respect to $g$;

(d) $S\left(A_{0}\right) \subseteq B_{0}$;

(e) $A_{0} \subseteq g\left(A_{0}\right)$.

Then there exists a unique point $x \in A$ such that

$$
d(g x, S x)=d(A, B) .
$$

Moreover, for any fixed $x_{0} \in A_{0}$, the sequence $\left\{x_{n}\right\}$ defined by

$$
d\left(g x_{n+1}, S x_{n}\right)=d(A, B)
$$

converges to the element $x$.

On the other hand, a sequence $\left\{u_{n}\right\}$ in A converges to $x$ if there exists a sequence $\left\{\epsilon_{n}\right\}$ of positive numbers such that

$$
\lim _{n \rightarrow \infty} \epsilon_{n}=0, \quad d\left(u_{n+1}, z_{n+1}\right) \leq \epsilon_{n},
$$

where $z_{n+1} \in A$ satisfies the condition that $d\left(g z_{n+1}, S u_{n}\right)=d(A, B)$.

Proof Since $S\left(A_{0}\right) \subseteq B_{0}$ and $A_{0} \subseteq g\left(A_{0}\right)$, as in the proof of Theorem 3.3, we can construct the sequence $\left\{x_{n}\right\}$ in $A_{0}$ such that

$$
d\left(g x_{n+1}, S x_{n}\right)=d(A, B)
$$

for each $n \geq 1$. Since $g$ is an isometry and $S$ is Geraghty's proximal contraction of the first kind, we see that

$$
d\left(x_{n}, x_{n+1}\right)=d\left(g x_{n}, g x_{n+1}\right) \leq \beta\left(d\left(x_{n}, x_{n-1}\right)\right) d\left(x_{n}, x_{n-1}\right)
$$

for all $n \geq 1$. Again, similarly, we can show that the sequence $\left\{x_{n}\right\}$ is a Cauchy sequence and so it converges to some $x \in A$. Since $S$ is Geraghty's proximal contraction of the second 
kind and preserves the isometric distance with respect to $g$, we have

$$
\begin{aligned}
d\left(S x_{n}, S x_{n+1}\right) & =d\left(S g x_{n}, S g x_{n+1}\right) \\
& \leq \beta\left(d\left(S x_{n-1}, S x_{n}\right)\right) d\left(S x_{n-1}, S x_{n}\right) \\
& \leq d\left(S x_{n-1}, S x_{n}\right)
\end{aligned}
$$

which means that the sequence $\left\{d\left(S x_{n+1}, S x_{n}\right)\right\}$ is non-increasing and bounded below. Hence there exists $r \geq 0$ such that

$$
\lim _{n \rightarrow \infty} d\left(S x_{n+1}, S x_{n}\right)=r
$$

Suppose that $r>0$. Observe that

$$
\frac{d\left(S x_{n}, S x_{n+1}\right)}{d\left(S x_{n-1}, S x_{n}\right)} \leq \beta\left(d\left(S x_{n-1}, S x_{n}\right)\right) .
$$

Taking $k \rightarrow \infty$ in the above inequality, we get $\beta\left(d\left(S x_{n-1}, S x_{n}\right)\right) \rightarrow 1$. Since $\beta \in \mathcal{S}$, we have $r=0$ which is a contradiction and thus

$$
\lim _{n \rightarrow \infty} d\left(S x_{n+1}, S x_{n}\right)=0 .
$$

Now, we claim that $\left\{S x_{n}\right\}$ is a Cauchy sequence. Suppose that $\left\{S x_{n}\right\}$ is not a Cauchy sequence. Then there exists $\varepsilon>0$ and subsequences $\left\{S x_{m_{k}}\right\},\left\{S x_{n_{k}}\right\}$ of $\left\{S x_{n}\right\}$ such that, for any $n_{k}>m_{k} \geq k$,

$$
r_{k}:=d\left(S x_{m_{k}}, S x_{n_{k}}\right) \geq \varepsilon, \quad d\left(S x_{m_{k}}, S x_{n_{k}-1}\right)<\varepsilon
$$

for any $k \in\{1,2,3, \ldots\}$. For each $n \geq 1$, let $\gamma_{n}:=d\left(S x_{n+1}, S x_{n}\right)$. Then we have

$$
\begin{aligned}
\varepsilon & \leq r_{k} \leq d\left(S x_{m_{k}}, S x_{n_{k}-1}\right)+d\left(S x_{n_{k}-1}, S x_{n_{k}}\right) \\
& <\varepsilon+\gamma_{n_{k}-1}
\end{aligned}
$$

and so it follows from (3.17) and (3.18) that

$$
\lim _{k \rightarrow \infty} r_{k}=\varepsilon
$$

Notice also that

$$
\begin{aligned}
\varepsilon & \leq r_{k} \\
& \leq d\left(S x_{m_{k}}, S x_{m_{k}+1}\right)+d\left(S x_{n_{k}+1}, S x_{n_{k}}\right)+d\left(S x_{m_{k}+1}, S x_{n_{k}+1}\right) \\
& =\gamma_{m_{k}}+\gamma_{n_{k}}+d\left(S x_{m_{k}+1}, S x_{n_{k}+1}\right) \\
& \leq \gamma_{m_{k}}+\gamma_{n_{k}}+\beta\left(d\left(S x_{m_{k}}, S x_{n_{k}}\right)\right) d\left(S x_{m_{k}}, S x_{n_{k}}\right) .
\end{aligned}
$$

So, it follows that

$$
1=\lim _{k \rightarrow \infty} \frac{r_{k}-\gamma_{m_{k}}-\gamma_{n_{k}}}{d\left(S x_{m_{k}}, S x_{n_{k}}\right)} \leq \lim _{k \rightarrow \infty} \beta\left(d\left(S x_{m_{k}}, S x_{n_{k}}\right)\right)<1
$$


and so $\lim _{k \rightarrow \infty} \beta\left(d\left(S x_{m_{k}}, S x_{n_{k}}\right)\right)=1$. Since $\beta \in \mathcal{S}$, we have $\lim _{k \rightarrow \infty} d\left(S x_{m_{k}}, S x_{n_{k}}\right)=0$, that is, $\varepsilon=0$, which is a contradiction. So, we obtain the claim and then it converges to some $y \in B$. Therefore, we can conclude that

$$
d(g x, y)=\lim _{n \rightarrow \infty} d\left(g x_{n+1}, S x_{n}\right)=d(A, B)
$$

which implies that $g x \in A_{0}$. Since $A_{0} \subseteq g\left(A_{0}\right)$, we have $g x=g z$ for some $z \in A_{0}$ and then $d(g x, g z)=0$. By the fact that $g$ is an isometry, we have $d(x, z)=d(g x, g z)=0$. Hence $x=z$ and so $x \in A_{0}$. Since $S\left(A_{0}\right) \subseteq B_{0}$, there exists $u \in A$ such that

$$
d(u, S x)=d(A, B)
$$

Since $S$ is Geraghty's proximal contraction of the first kind, it follows from (3.16) and (3.19) that

$$
d\left(u, g x_{n+1}\right) \leq \beta\left(d\left(x, x_{n}\right)\right) d\left(x, x_{n}\right)
$$

for all $n \geq 1$. Taking $n \rightarrow \infty$ in (3.20), it follows that the sequence $\left\{g x_{n}\right\}$ converges to a point $u$. Since $g$ is continuous and $\lim _{n \rightarrow \infty} x_{n}=x$, we have $g x_{n} \rightarrow g x$ as $n \rightarrow \infty$. By the uniqueness of the limit, we conclude that $u=g x$. Therefore, it follows that $d(g x, S x)=$ $d(u, S x)=d(A, B)$.

The uniqueness and the remaining part of the proof follow from the proof of Theorem 3.3. This completes the proof.

If $g$ is the identity mapping in Theorem 3.7, then we obtain the following.

Corollary 3.8 Let $(X, d)$ be a complete metric space and let $A, B$ be nonempty closed subsets of $X$. Further, suppose that $A_{0}$ and $B_{0}$ are nonempty. Let $S: A \rightarrow B$ be the mappings satisfying the following conditions:

(a) $S$ is Geraghty's proximal contraction of the first and second kinds;

(b) $S\left(A_{0}\right) \subseteq B_{0}$.

Then there exists a unique point $x \in A$ such that

$$
d(x, S x)=d(A, B) .
$$

Moreover, for any fixed $x_{0} \in A_{0}$, the sequence $\left\{x_{n}\right\}$ defined by

$$
d\left(x_{n+1}, S x_{n}\right)=d(A, B)
$$

converges to the best proximity point $x$ of $S$.

If we take $\beta(t)=k$ in Theorem 3.7, where $0 \leq k<1$, we obtain the following.

Corollary 3.9 [26] Let $(X, d)$ be a complete metric space and let $A, B$ be nonempty closed subsets of $X$. Further, suppose that $A_{0}$ and $B_{0}$ are nonempty. Let $S: A \rightarrow B$ and $g: A \rightarrow A$ be the mappings satisfying the following conditions:

(a) $S$ is a proximal contraction of the first and second kinds; 
(b) $g$ is an isometry;

(c) S preserves isometric distance with respect to $g$;

(d) $S\left(A_{0}\right) \subseteq B_{0}$;

(e) $A_{0} \subseteq g\left(A_{0}\right)$.

Then there exists a unique point $x \in A$ such that

$$
d(g x, S x)=d(A, B) .
$$

Moreover, for any fixed $x_{0} \in A_{0}$, the sequence $\left\{x_{n}\right\}$ defined by

$$
d\left(g x_{n+1}, S x_{n}\right)=d(A, B)
$$

converges to the element $x$.

If $g$ is the identity mapping in Corollary 3.9, then we obtain the following.

Corollary 3.10 Let $(X, d)$ be a complete metric space and let $A, B$ be nonempty closed subsets of $X$. Further, suppose that $A_{0}$ and $B_{0}$ are nonempty. Let $S: A \rightarrow B$ be a mapping satisfying the following conditions:

(a) $S$ is a proximal contraction of the first and second kinds;

(b) $S\left(A_{0}\right) \subseteq B_{0}$.

Then there exists a unique point $x \in A$ such that

$$
d(x, S x)=d(A, B) .
$$

Moreover, for any fixed $x_{0} \in A_{0}$, the sequence $\left\{x_{n}\right\}$ defined by

$$
d\left(x_{n+1}, S x_{n}\right)=d(A, B)
$$

converges to the best proximity point $x$ of $S$.

\section{Examples}

Next, we give an example to show that Definition 3.1 is different from Definition 2.1; moreover, we give an example which supports Theorem 3.3. First, we give some proposition for our example as follows.

Proposition 4.1 Let $f:[0, \infty) \rightarrow[0, \infty)$ be a function defined by $f(t)=\ln (1+t)$. Then we have the following inequality:

$$
f(a)-f(b) \leq f(|a-b|)
$$

for all $a, b \in[0, \infty)$.

Proof If $x=y$, we have done. Suppose that $x>y$. Then since we have

$$
\frac{1+x}{1+y}=\frac{1+x+y-y}{1+y}=1+\frac{x-y}{1+y}<1+|x-y|,
$$


it follows that $\ln (1+x)-\ln (1+y)<\ln (1+|x-y|)$. In the case $x<y$, by a similar argument, we can prove that inequality (4.1) holds.

Proposition 4.2 For each $x, y \in \mathbb{R}$, we have that the following inequality holds:

$$
\frac{1}{(1+|x|)(1+|y|)} \leq \frac{1}{1+|x-y|}
$$

Proof Since

$$
\begin{aligned}
1+|x-y| & \leq 1+|x|+|y| \\
& \leq 1+|x|+|y|+|x||y| \\
& =(1+|x|)(1+|y|),
\end{aligned}
$$

so that

$$
\frac{1}{(1+|x|)(1+|y|)} \leq \frac{1}{1+|x-y|}
$$

Example 4.3 Consider the complete metric space $\mathbb{R}^{2}$ with Euclidean metric. Let

$$
A=\{(0, x): x \in \mathbb{R}\}, \quad B=\{(2, y): y \in \mathbb{R}\} .
$$

Then $d(A, B)=2$. Define the mappings $S: A \rightarrow B$ as follows:

$$
S((0, x))=(2, \ln (1+|x|)) .
$$

First, we show that $S$ is Geraghty's proximal contractions of the first kind with $\beta \in \mathcal{S}$ defined by

$$
\beta(t)= \begin{cases}1, & t=0, \\ \frac{\ln (1+t)}{t}, & t>0 .\end{cases}
$$

Let $\left(0, x_{1}\right),\left(0, x_{2}\right),\left(0, a_{1}\right)$ and $\left(0, a_{2}\right)$ be elements in $A$ satisfying

$$
d\left(\left(0, a_{1}\right), S\left(0, x_{1}\right)\right)=d(A, B)=2, \quad d\left(\left(0, a_{2}\right), S\left(0, x_{2}\right)\right)=d(A, B)=2 .
$$

Then we have $a_{i}=\ln \left(1+\left|x_{i}\right|\right)$ for $i=1,2$. If $x_{1}=x_{2}$, we have done. Assume that $x_{1} \neq x_{2}$. Then, by Proposition 4.1 and the fact that the function $f(x)=\ln (1+t)$ is increasing, we have

$$
\begin{aligned}
d\left(\left(0, a_{1}\right),\left(0, a_{2}\right)\right) & =d\left(\left(0, \ln \left(1+\left|x_{1}\right|\right)\right),\left(0, \ln \left(1+\left|x_{2}\right|\right)\right)\right) \\
& =\left|\ln \left(1+\left|x_{1}\right|\right)-\ln \left(1+\left|x_{2}\right|\right)\right| \\
& \leq\left|\ln \left(1+|| x_{1}|-| x_{2}||\right)\right| \\
& \leq\left|\ln \left(1+\left|x_{1}-x_{2}\right|\right)\right|
\end{aligned}
$$




$$
\begin{aligned}
& =\frac{\left|\ln \left(1+\left|x_{1}-x_{2}\right|\right)\right|}{\left|x_{1}-x_{2}\right|}\left|x_{1}-x_{2}\right| \\
& =\beta\left(d\left(\left(0, x_{1}\right),\left(0, x_{2}\right)\right)\right) d\left(\left(0, x_{1}\right),\left(0, x_{2}\right)\right) .
\end{aligned}
$$

Thus $S$ is Geraghty's proximal contraction of the first kind.

Next, we prove that $S$ is not a proximal contraction of the first kind. Suppose $S$ is a proximal contraction of the first kind, then for each $\left(0, x^{*}\right),\left(0, y^{*}\right),\left(0, a^{*}\right),\left(0, b^{*}\right) \in A$ satisfying

$$
d\left(\left(0, x^{*}\right), S\left(0, a^{*}\right)\right)=d(A, B)=2 \quad \text { and } \quad d\left(\left(0, y^{*}\right), S\left(0, b^{*}\right)\right)=d(A, B)=2,
$$

there exists $k \in[0,1)$ such that

$$
d\left(\left(0, x^{*}\right),\left(0, y^{*}\right)\right) \leq k d\left(\left(0, a^{*}\right),\left(0, b^{*}\right)\right) .
$$

From (4.2), we get $x^{*}=\ln \left(1+\left|a^{*}\right|\right)$ and $y^{*}=\ln \left(1+\left|b^{*}\right|\right)$ and so

$$
\begin{aligned}
\left|\ln \left(1+\left|a^{*}\right|\right)-\ln \left(1+\left|b^{*}\right|\right)\right| & =d\left(\left(0, x^{*}\right),\left(0, y^{*}\right)\right) \\
& \leq k d\left(\left(0, a^{*}\right),\left(0, b^{*}\right)\right) \\
& =k\left|a^{*}-b^{*}\right| .
\end{aligned}
$$

Letting $b^{*}=0$, we get

$$
1=\lim _{\left|a^{*}\right| \rightarrow 0^{+}} \frac{\left|\ln \left(1+\left|a^{*}\right|\right)\right|}{\left|a^{*}\right|} \leq k<1,
$$

which is a contradiction. Thus $S$ is not a proximal contraction of the first kind.

Example 4.4 Consider the complete metric space $\mathbb{R}^{2}$ with metric defined by

$$
d\left(\left(x_{1}, x_{2}\right),\left(y_{1}, y_{2}\right)\right)=\left|x_{1}-y_{1}\right|+\left|x_{2}-y_{2}\right|
$$

for all $\left(x_{1}, x_{2}\right),\left(y_{1}, y_{2}\right) \in \mathbb{R}^{2}$. Let

$$
A=\{(0, x): x \in \mathbb{R}\}, \quad B=\{(2, y): y \in \mathbb{R}\} .
$$

Define two mappings $S: A \rightarrow B, T: B \rightarrow A$ and $g: A \cup B \rightarrow A \cup B$ as follows:

$$
S((0, x))=\left(2, \frac{|x|}{2(1+|x|)}\right), \quad T((2, y))=\left(0, \frac{|y|}{2(1+|y|)}\right), \quad g((x, y))=(x,-y) .
$$

Then $d(A, B)=2, A_{0}=A, B_{0}=B$ and the mapping $g$ is an isometry.

Next, we show that $S$ and $T$ are Geraghty's proximal contractions of the first kind with $\beta \in \mathcal{S}$ defined by

$$
\beta(t)=\frac{1}{1+t} \quad \text { for all } t \geq 0 .
$$


Let $\left(0, x_{1}\right),\left(0, x_{2}\right),\left(0, a_{1}\right)$ and $\left(0, a_{2}\right)$ be elements in $A$ satisfying

$$
d\left(\left(0, a_{1}\right), S\left(0, x_{1}\right)\right)=d(A, B)=2, \quad d\left(\left(0, a_{2}\right), S\left(0, x_{2}\right)\right)=d(A, B)=2 .
$$

Then we have

$$
a_{i}=\frac{\left|x_{i}\right|}{2\left(1+\left|x_{i}\right|\right)} \quad \text { for } i=1,2 .
$$

If $x_{1}=x_{2}$, we have done. Assume that $x_{1} \neq x_{2}$, then, by Proposition 4.2, we have

$$
\begin{aligned}
d\left(\left(0, a_{1}\right),\left(0, a_{2}\right)\right) & =d\left(\left(0, \frac{\left|x_{1}\right|}{2\left(1+\left|x_{1}\right|\right)}\right),\left(0, \frac{\left|x_{2}\right|}{2\left(1+\left|x_{2}\right|\right)}\right)\right) \\
& =\left|\frac{\left|x_{1}\right|}{2\left(1+\left|x_{1}\right|\right)}-\frac{\left|x_{2}\right|}{2\left(1+\left|x_{2}\right|\right)}\right| \\
& =\left|\frac{\left|x_{1}\right|-\left|x_{2}\right|}{2\left(1+\left|x_{1}\right|\right)\left(1+\left|x_{2}\right|\right)}\right| \\
& \leq\left|\frac{x_{1}-x_{2}}{\left(1+\left|x_{1}\right|\right)\left(1+\left|x_{2}\right|\right)}\right| \\
& \leq \frac{1}{1+\left|x_{1}-x_{2}\right|}\left|x_{1}-x_{2}\right| \\
& =\beta\left(d\left(\left(0, x_{1}\right),\left(0, x_{2}\right)\right)\right) d\left(\left(0, x_{1}\right),\left(0, x_{2}\right)\right) .
\end{aligned}
$$

Thus $S$ is Geraghty's proximal contraction of the first kind. Similarly, we can see that $T$ is Geraghty's proximal contraction of the first kind. Next, we show that the pair $(S, T)$ is a proximal cyclic contraction. Let $(0, u),(0, x) \in A$ and $(2, v),(2, y) \in B$ be such that

$$
d((0, u), S(0, x))=d(A, B)=2, \quad d((2, v), T(2, y))=d(A, B)=2 .
$$

Then we get

$$
u=\frac{|x|}{2(1+|x|)}, \quad v=\frac{|y|}{2(1+|y|)} .
$$

In the case $x=y$, clear. Suppose that $x \neq y$, then we have

$$
\begin{aligned}
d((0, u),(2, v)) & =|u-v|+2 \\
& =\left|\frac{|x|}{2(1+|x|)}-\frac{|y|}{2(1+|y|)}\right|+2 \\
& =\left|\frac{|x|-|y|}{2(1+|x|)(1+|y|)}\right|+2 \\
& \leq \frac{|x-y|}{2(1+|x|)(1+|y|)}+2 \\
& \leq \frac{1}{2}|x-y|+2 \\
& \leq k(|x-y|+2)+(1-k) 2 \\
& =k d((0, x),(2, y))+(1-k) d(A, B),
\end{aligned}
$$


where $k=\left[\frac{1}{2}, 1\right)$. Hence the pair $(S, T)$ is a proximal cyclic contraction. Therefore, all the hypotheses of Theorem 3.3 are satisfied. Further, it is easy to see that $(0,0) \in A$ and $(2,0) \in$ $B$ are the unique elements such that

$$
d(g(0,0), S(0,0))=d(g(2,0), T(2,0))=d((0,0),(2,0))=d(A, B) .
$$

\section{Conclusions}

This article has investigated the existence of an optimal approximate solution, the socalled best proximity point, for the generalized notion of proximal contractions of the first and second kinds, which were defined by Sadiq Basha in [26]. Furthermore, an algorithm for computing such an optimal approximate solution and example which supports our main results have been presented.

Competing interests

The authors declare that they have no competing interests.

Authors' contributions

All authors contributed equally and significantly in this research. All authors read and approved the final manuscript.

\section{Author details}

'Department of Mathematics, Faculty of Science, King Mongkut's University of Technology Thonburi (KMUTT), Bang Mod, Bangkok, 10140, Thailand. 'Department of Mathematics Education and the RINS, Gyeongsang National University, Chinju, 660-701, Korea. ${ }^{3}$ Department of Mathematics, Faculty of Liberal Arts and Science, Kasetsart University, Kamphaeng-Saen Campus, Nakhon Pathom, 73140, Thailand.

\section{Acknowledgements}

Mr. Chirasak Mongkolkeha was supported from the Thailand Research Fund through the Royal Golden Jubilee Program under Grant PHD/0029/2553 for the Ph.D. Program at KMUTT, Thailand. This research was partially finished at Department of Mathematics Education, Gyeongsang National University, Republic of Korea. Also, the second author was supported by the Basic Science Research Program through the National Research Foundation of Korea (NRF) funded by the Ministry of Education, Science, and Technology (Grant No. 2012-0008170). The third author was supported by the Commission on Higher Education, the Thailand Research Fund and the King Mongkut's University of Technology Thonburi (Grant No. MRG5580213).

Received: 20 February 2013 Accepted: 15 June 2013 Published: 8 July 2013

\section{References}

1. Fan, K: Extensions of two fixed point theorems of F.E. Browder. Math. Z. 112, 234-240 (1969)

2. Prolla, JB: Fixed point theorems for set valued mappings and existence of best approximations. Numer. Funct. Anal. Optim. 5, 449-455 (1982-1983)

3. Reich, S: Approximate selections, best approximations, fixed points and invariant sets. J. Math. Anal. Appl. 62, 104-113 (1978)

4. Sehgal, VM, Singh, SP: A generalization to multifunctions of Fan's best approximation theorem. Proc. Am. Math. Soc 102, 534-537 (1988)

5. Sehgal, VM, Singh, SP: A theorem on best approximations. Numer. Funct. Anal. Optim. 10, 181-184 (1989)

6. Al-Thagafi, MA, Shahzad, N: Convergence and existence results for best proximity points. Nonlinear Anal. 70(10), 3665-3671 (2009)

7. Eldred, AA, Veeramani, P: Existence and convergence of best proximity points. J. Math. Anal. Appl. 323, 1001-1006 (2006)

8. Caballero, J, Harjani, J, Sadarangani, K: A best proximity point theorem for Geraghty-contractions. Fixed Point Theory Appl. 2012, 231 (2012). doi:10.1186/1687-1812-2012-231

9. Di Bari, C, Suzuki, T, Vetro, C: Best proximity points for cyclic Meir-Keeler contractions. Nonlinear Anal. 69(11), 3790-3794 (2008)

10. Karpagam, S, Agrawal, S: Best proximity point theorems for $p$-cyclic Meir-Keeler contractions. Fixed Point Theory Appl. 2009, Article ID 197308 (2009)

11. Suzuki, T, Kikkawa, M, Vetro, C: The existence of best proximity points in metric spaces with the property UC. Nonlinear Anal. 71, 2918-2926 (2009)

12. Vetro, C: Best proximity points: convergence and existence theorems for $p$-cyclic mappings. Nonlinear Anal. 73(7), 2283-2291 (2010)

13. Wlodarczyk, K, Plebaniak, R, Banach, A: Erratum to: 'Best proximity points for cyclic and noncyclic set-valued relatively quasi-asymptotic contractions in uniform spaces.' Nonlinear Anal. 71, 3583-3586 (2009)

14. Wlodarczyk, K, Plebaniak, R, Obczynski, C: Convergence theorems, best approximation and best proximity for set-valued dynamic systems of relatively quasi-asymptotic contractions in cone uniform spaces. Nonlinear Anal. 72, 794-805 (2010) 
15. Agarwal, RP, El-Gebeily, MA, O’Regan, D: Generalized contractions in partially ordered metric spaces. Appl. Anal. 87(1), 109-116 (2008)

16. Boyd, DW, Wong, JSW: On nonlinear contractions. Proc. Am. Math. Soc. 20, 458-464 (1969)

17. Mongkolkeha, C, Sintunavarat, W, Kumam, P: Fixed point theorems for contraction mappings in modular metric spaces. Fixed Point Theory Appl. 2011, 93 (2011). doi:10.1186/1687-1812-2011-93

18. Sintunavarat, W, Cho, YJ, Kumam, P: Common fixed point theorems for c-distance in ordered cone metric spaces. Comput. Math. Appl. 62, 1969-1978 (2011)

19. Geraghty, M: On contractive mappings. Proc. Am. Math. Soc. 40, 604-608 (1973)

20. Eldred, AA, Kirk, WA, Veeramani, P: Proximinal normal structure and relatively nonexpanisve mappings. Stud. Math. 171(3), 283-293 (2005)

21. Amini-Harandi, A: Best proximity points for proximal generalized contractions in metric spaces. Optim. Lett. (2012). doi:10.1007/s11590-012-0470-z

22. Al-Thagafi, MA, Shahzad, N: Best proximity sets and equilibrium pairs for a finite family of multimaps. Fixed Point Theory Appl. 2008, Article ID 457069 (2008)

23. Kim, WK, Kum, S, Lee, KH: On general best proximity pairs and equilibrium pairs in free abstract economies. Nonlinear Anal. 68(8), 2216-2227 (2008)

24. Mongkolkeha, C, Kumam, P: Best proximity point theorems for generalized cyclic contractions in ordered metric spaces. J. Optim. Theory Appl. (2012). doi:10.1007/s10957-012-9991-y

25. Wlodarczyk, K, Plebaniak, R, Banach, A: Best proximity points for cyclic and noncyclic set-valued relatively quasi-asymptotic contractions in uniform spaces. Nonlinear Anal. 70(9), 3332-3341 (2009)

26. Sadiq Basha, S: Best proximity point theorems generalizing the contraction principle. Nonlinear Anal. 74, 5844-5850 (2011)

27. Sadiq Basha, S, Veeramani, P: Best proximity pair theorems for multifunctions with open fibres. J. Approx. Theory 103, 119-129 (2000)

doi:10.1186/1687-1812-2013-180

Cite this article as: Mongkolkeha et al.: Best proximity points for Geraghty's proximal contraction mappings. Fixed Point Theory and Applications 2013 2013:180.

\section{Submit your manuscript to a SpringerOpen ${ }^{\odot}$ journal and benefit from:}

- Convenient online submission

- Rigorous peer review

- Immediate publication on acceptance

- Open access: articles freely available online

- High visibility within the field

- Retaining the copyright to your article 